\title{
Correction to: Primary intracranial Ewing sarcoma/ peripheral primitive neuroectodermal tumor, an entity of unacquaintance: a series of 8 cases
}

\author{
Gauri Deshpande ${ }^{1} \cdot$ Sridhar Epari $^{1}$ (1) $\cdot$ Chhavi Gupta $^{1} \cdot$ Omshree Shetty $^{1} \cdot$ Mamta Gurav $^{1} \cdot$ Girish Chinnaswamy $^{2}$. \\ Aliasgar Moiyadi ${ }^{3} \cdot$ Tejpal Gupta $^{4}$
}

Published online: 19 September 2020

(C) Springer-Verlag GmbH Germany, part of Springer Nature 2020

\section{Correction to: Child's Nervous System https://doi.org/10.1007/s00381-020-04850-w}

Due to an internal mistake during production the name of one of the co-authors, Aliasgar Moiyadi, was omitted from the original publication. With this Erratum the name of the coauthor is included again and the original publication has been modified accordingly. SpringerNature apologizes for this and for any inconvenience associated therewith.

The original article has been corrected.

Publisher's note Springer Nature remains neutral with regard to jurisdictional claims in published maps and institutional affiliations.

The online version of the original article can be found at https://oi.org/ 10.1007/s00381-020-04850-w

Sridhar Epari

sridhep@gmail.com

1 Department of Pathology (\& Division of Molecular Pathology), Tata Memorial Hospital and ACTREC, Tata Memorial Centre, Homi Bhabha National Institute, 8th Floor, Annexe Building, Dr. E. Borges Road, Parel, Mumbai 400012, India

2 Department of Pediatric Oncology, Tata Memorial Centre, Homi Bhabha National Institute, Mumbai, India

3 Division of Neurosurgery, Department of Surigcal Oncology, Tata Memorial Hospital and ACTREC, Tata Memorial Centre, Homi Bhabha National Institute, Mumbai, India

4 Department of Radiation Oncology, Tata Memorial Hospital and ACTREC, Tata Memorial Centre, Homi Bhabha National Institute, Mumbai, India 